Commentary

See articles on pages 629 and 634

\title{
Helicobacter pylori: is it all in the family?
}

The epidemiology of Helicobacter pylori infection has been extensively studied in recent years but there is still uncertaintly about its mode of transmission. Speculation about environmental and animal reservoirs for the infection continues but the weight of evidence suggests that it is mainly transmitted directly from one human to another. Faecal-oral, ${ }^{1}$ oro-oral, ${ }^{2}$ and gastro-oral ${ }^{3}$ (contact with vomitus or gastric secretions) routes of transmission have been proposed.

The infection is much commoner in developing nations than in Western countries and there is a clear association with poorer socio-economic status and home overcrowding. Recent studies have suggested that acquisition in Western countries occurs mainly in childhood. ${ }^{4}{ }^{5}$ Also, adults who have been infected and developed a duodenal ulcer seem to have a relatively low risk of re-infection after eradication therapy ${ }^{6}$ yet these are the patients in whom we might speculate that there is a predisposition to be infected, whether it be a genetic or environmental trigger.

Two papers in this issue of Gut look specifically at the possibility of spouse to spouse transmission of $H$ pylori. Parente and colleagues have reported a higher prevalence of infection in spouses of $H$ pylori infected duodenal ulcer patients than in a control population of blood donors matched for age, sex, geographical location, and socioeconomic status (see page 629). Furthermore, they have shown that infected spouses are more likely to have dyspeptic symptoms than those without the infection and that those with dyspepsia and $H$ pylori have a high prevalence of peptic ulceration and erosions. Georgopoulos and colleagues also noted that spouses of $H$ pylori infected duodenal ulcer patients were much more likely to be infected with the organism than spouses of $H$ pylori negative duodenal ulcer patients (see page 634). They extended this observation by assessing the ribopatterns of $H$ pylori strains derived from 18 duodenal ulcer patients and their spouses who were also infected. In eight families, there was a single strain of $H$ pylori infecting both partners whereas in the other 10 families, each partner was infected with a different strain.

Is the case for spouse to spouse transmission of infection proved by these reports? The first study is well designed but interpretation hinges fully on the appropriateness of the control population. On the surface, the control subjects seem to be well chosen but all were blood donors, a lifestyle choice which in itself may reflect some hidden bias or attitude towards health and hygiene. Also, although socioeconomic status was controlled for, the specific question of overcrowding and bed sharing in childhood was not considered. ${ }^{7}$ It remains feasible that these infected spouses acquired their infection in childhood and not from their partners. The second study provides stronger evidence for some infections being transmitted from spouse to spouse.
However, we are not told how often we could expect to see the same strain of $H$ pylori in two partners in a marriage by chance if there was no spouse to spouse transmission nor are we given information about the range of strains of $H$ pylori in the geographical area from which the study patients were derived and which can be reliably distinguished by the ribotyping techniques used. Thus, the case for spouse to spouse transmission of $H$ pylori is suggested but not proved by these studies and further research is needed in this area before the implications for clinical practice can be assessed.

Longitudinal studies, following up families in which only one spouse is infected will provide the strongest evidence for intra-familial spread of the infection in the same way that spouse to spouse transmission of hepatitis $C$ has been evaluated. Other factors such as density of infection in the spouse's stomach and the presence of children ${ }^{8}$ or pets ${ }^{9}$ in the family may determine the likelihood of intra-familial spread and need to be considered in any future research. We already know that ulcer patients who have been treated by $H$ pylori eradication therapy have a very low risk of becoming re-infected ${ }^{6}$ and it is likely that many of these patients have infected spouses. Thus, it is premature to recommend screening of family members of ulcer patients if the aim is to minimise the risk of a treated patient being re-infected. The case for treating asymptomatic subjects with $H$ pylori infection is not proved though the observation of Parente and colleagues that infected spouses with dyspeptic symptoms had a high prevalence of peptic ulceration highlights the need to investigate symptomatic family members.

BRENDAN J COLLINS Department of Gastroenterology, Royal Perth Hospital, GPO Box X2213, Perth Western Australia 6001

1 Thomas JE, Gibson GR, Darboe MK, Dale A, Weaver LT. Isolation of Helicobacter pylori from human faeces. Lancet 1992; 340: 1194-5.

2 Krajden S, Fuksa M, Anderson J, et al. Examination of human stomach biopsies, saliva and dental plaque for Campylobacter pylori. $f$ Clin Microbiol 1989; 27: 1397-8.

3 Axon ATR. Is Helicobacter pylori transmitted by the gastro-oral route? Aliment Pharmacol Ther 1995; 9: 585-8.

4 Cullen DJE, Collins BJ, Christiansen KJ, Epis J, Warren JR, Surveyor I, et al. When is Helicobacter pylori infection acquired? Gut 1993; 34: 1681-2.

5 Parsonnet J, Blaser MJ, Perez-Perez GI, Hargrett-Bean N, Tauxe RV. Symptoms and risk factors of Helicobacter pylori infection in a cohort of epidemiologists. Gastroenterology 1992; 102: 41-6.

6 Forbes GM, Glaser ME, Cullen DJE, Warren JR, Christiansen K, Marshall BJ et al. Duodenal ulcer treated with Helicobacter pylori eradication: BJ et al. Duodenal ulcer treated with Helicobact
seven year follow up. Lancet 1994; 343: 258-60.

7 McCallion WA, Murray LJ, Bailie AG, Dalzell AM, O'Reilly DPJ, Bamford KB. Helicobacter pylori infection in children: relation with current KB. Helicobacter pylori infection in children:

8 Mitchell J, Mitchell HM, Tobias V. Acute Helicobacter pylori infection in an infant, associated with gastric ulceration and serological evidence of intra-familial transmission. Am f Gastroenterol 1992; 87: 382-6.

9 JG Fox. Non-human reservoirs of Helicobacter pylori. Aliment Pharmacol Ther 1995; 9 (suppl 2): 93-103. 